\title{
Debate de infertilidad: Impacto en la comunidad, ¿Por qué es la familia el núcleo de la Sociedad?
}

\author{
Padre Virgilio Zea*
}

\section{¿Qué es la sociedad?}

Se la podría caracterizar como el ente formado por personas que constituyen grupos interactivos que, a través de la diversidad de sus aportes y funciones permiten promover la creación de un proyecto humano solidario; en ella cada persona juega un papel importante: es el centro y la fuente de la creatividad; pero sus posibilidades creativas no llegarían a desarrollarse sin el don de los demás; por otra parte la iniciativa de cada persona es potenciada por los grupos de que forma parte, por los objetivos comunes que éstos buscan y por la creación de un sentido de responsabilidad compartida en la solución de los problemas y en el avance de la sociedad.

\section{¿Qué es la persona, cómo nos hacemos personas?}

En este marco de la sociedad es imprescindible dar una descripción que permita acercarse a una comprensión integral de la persona y que ofrezca una visión antropológica desde la cual se pueda abordar el problema: ¿Por qué es la familia el núcleo de la sociedad? Y esto dentro del marco de la infertilidad y su impacto en la sociedad.

\section{Avance de la ciencia y autocomprensión del hombre}

Hemos de ser conscientes de que los avances de la ciencia, causados por el hombre y fruto de su ingenio creativo, (Concilio Vaticano II, G. Spes. No. 4-5, 7) han cambiado profundamente nuestra forma de entendernos: el hombre no sólo hace cosas, sino que al transformar la realidad se hace a sí mismo y al hacerse logra entender mejor el misterio de su existencia.

Los avances de la ciencia son obra de las personas, gracias a su trabajo e ingenio, a su curiosidad, a su ansia de progreso y de conquistas.

El científico, los políticos, los economistas, son cada vez más conscientes de que las transformaciones científico técnicas han cambiado el rostro del mundo y de que el hombre es el creador y el orientador de la historia, quien le traza sus metas y los pasos de su desarrollo.

Simultáneamente la conciencia de la limitación del obrar humano lo tortura como una llaga abierta: el avance de la ciencia puede llevar a la destrucción total de la

Doctor en Teología. Universidad Gregoriana, Roma. Profesor de Teologia y Etica. Universidad Javeriana. naturaleza y de la humanidad; todo el potencial tecnológico se puede orientar hacia la producción y comercialización de armas y consiguientemente a la generación de guerras o a construir la paz, en el respeto y responsabilidad mutuos.

Esta capacidad de hacer la historia plantea la pregunta: ¿En qué clase de mundo queremos vivir y qué herencia vamos a dejar a nuestros hijos?

\section{Una descripción integral del hombre}

Algunas antropologías describen la persona como ser bio-psicosocial; gracias a estas características, todo niño recibe una herencia genética y se integra en un mundo de relaciones interpersonales, comunitarias y sociales que configurarán, en gran medida, la forma como se autovalora y se sitúa ante la tarea de hacerse a sí mismo. Además la persona se inserta en una cultura, indispensable para comprenderse a sí misma.

A la descripción anterior le falta un aspecto: el espiritual, por el cual la persona se abre a las preguntas por el sentido, la meta y la razón de ser de la propia existencia y finalmente a la posibilidad de una relación personal con Dios, mediada por el mundo en que se hace persona.

Ahondar en el ser interpersonal permite comprender que el hombre existe en cuanto llamado a la vida por el amor y la responsabilidad de sus padres; a esta llamada responderá por la forma como realice su existencia.

Nacido en el seno de una familia, debe hacerse a sí mismo en múltiples esquemas de relación: debe ser acogido por ella; la relación con las otras personas hará que se pueda insertar armónicamente en el mundo y tome conciencia de sus cualidades.

Al encontrar en sus padres, parientes, profesores, amigos, en la televisión modelos de identificación, al sintonizar con ellos, se siente bombardeado por múltiples y contradictorias invitaciones.

Los valores como la honestidad, el amor al trabajo, el sentido de pertenencia y de responsabilidad ante una comunidad y una patria se asimilan y se interiorizan, se hacen propios por el contacto amoroso y vivo con su medio ambiente interpersonal.

Allí capta aspectos de la persona indispensables para ser un ciudadano responsable:

- Comprende que la historia heredada es fruto de la entrega y sacrificio de los padres y de cada ciudadano.

- Del empeño creativo de quienes soñaron y realizaron para él un futuro con nuevas posibilidades, de quienes en cada enfermedad, en cada acontecimiento: 
la muerte, el dolor, encontraron una interpelación, un llamado al compromiso y a realizar una historia más humana.

En esta perspectiva y desde la entrega de los mayores en favor nuestro, comprendemos que la libertad no consiste en hacer lo que nos plazca, sino en el asumir la vida responsablemente y en una decisión que se concrete, en el esfuerzo por construir, en solidaridad con los demás, un mundo verdaderamente humano.

Más aún, la responsabilidad, el sentido y el valor de la existencia son cualidades que se viven en su mayor profundidad cuando en el encuentro con nuestro mundo de personas, lo construimos a través de un amor responsable, creativo e histórico.

Las reflexiones anteriores parecen arrojar una conclusión clara: la persona no alcanza su madurez humana sino cuando conscientemente, desde un ambiente de amor y movida por el amor, se compromete en la creación de un mundo más humano.

\section{Importancia de la familia ¿Cuál familia?}

Pensaríamos de inmediato en una familia de dos esposos fecundos que viven en la fidelidad y el amor responsables.

Este ideal hay que promoverlo ayudando a los hijos en el desarrollo de una personalidad madura que integre la sexualidad de modo que el placer conyugal sea medio para el crecimiento personal y ayude, a la realización de un diálogo responsable y fiel de la pareja.

Este ideal familiar se destruye porque las múltiples formas de divorcio hacen que los niños crezcan en un ambiente enrarecido por las tensiones y el desafecto de sus padres y sobretodo porque al niño se lo manipula y se lo hace víctima del rechazo mutuo de los cónyuges.

Porque en no pocas familias el padrastro violento convierte el hogar en un infierno.

Porque son innumerables las madres, cabeza de familia, cuyos hijos, cada uno de un padre distinto, no encuentran modelos válidos de identificación.

Finalmente, porque el avance de la ciencia hace posible el nacimiento de una vida de parejas antes incapaces de engendrarla.

Este progreso de la ciencia ha traído como consecuencia una nueva autocomprensión del hombre y de su sexualidad.

Cuando considerábamos al mundo como una realidad estática y al hombre como una naturaleza con unos rasgos perfectamente determinados por Dios o por la biología, lo ético se buscaba por el sometimiento a la voluntad de Dios expresada por las leyes de la naturaleza supuestamente definibles por los rasgos biológicos de la pareja.

El avance de la ciencia nos ha hecho comprender no sólo la dinamicidad de la naturaleza y del hombre mismo, sino que lo verdaderamente humano no está ni escrito por Dios, ni determinado por la biología.

Encontrar lo verdaderamente humano es una tarea, una creación en la cual ha de involucrarse cada persona, cada familia, cada sociedad y el conjunto de las naciones porque formamos parte de un mundo cada vez más interdependiente.

\section{La infertilidad, ¿reto a la ciencia, a la ética y a la fe cristiana?}

Para abordar esta problemática hay que volver a la pregunta inicial de este trabajo: ¿Cómo entendemos al hombre?

La antropología y la fe pueden coincidir en un planteamiento básico: el mundo es un don de Dios al hombre; a éste, Dios lo llama a autoconstruirse con los otros en forma responsable, enfrentando los desafíos que le plantea la historia: el dolor, el sida, la guerra, el hambre, la infertilidad: son otros tantos retos que interpelan al hombre.

¿Cómo responde la ciencia a las ilusiones de una pareja infértil, que no puede realizar su capacidad creadora de la vida, una de las cualidades que la hace más semejante a Dios?

Es importante situar el problema en un marco más amplio:

El argumento del deseo de un hijo puede volverse ambiguo: en otras ocasiones, porque no se lo desea, se justifica su muerte por el aborto.

Por la ausencia del padre nace el niño de una fecundidad irresponsable. Extrañamente la sociedad y el padre se niegan a ser solidarios con la madre soltera, a la que sinembargo bombardearon con toda clase de incentivos para el amor fácil.

¿La sociedad debería educar para el amor maduro, capaz de responder a la mujer embarazada en actitud solidaria, de ayudarla a enfrentar el drama de un embarazo no deseado o que no se previno por inmadurez o ignorancia?

Cuando se aborda directamente el problema de la infertilidad, la ciencia quiere responder a un sueño truncado por un defecto de la naturaleza. No siendo la sexualidad un campo tabú, hay que establecer una analogía que hace lícitas y deseables las intervenciones en este terreno: aceptamos la moralidad de un trasplante de riñón, ¿cómo no aceptar la intervención en el terreno de la fertilidad? En los dos casos la ciencia busca superar un obstáculo o una deficiencia de la naturaleza.

Tomando la adopción como término análogo, se debe evitar que al niño se lo convierta en una prótesis para la felicidad de los padres: debe ser el centro del amor, valor en sí mismo y no medio para la felicidad de la pareja.

Conscientes de la diferencia que existe entre los procedimientos de fecundación artificial homólogos y heterólogos, hemos de recalcar que éste último introduce en la relación de la pareja un elemento extraño, que puede ser múltiple:

El aporte del semen de una tercera persona, o el alquiler de vientre o la implantación en el seno de la madre de óvulos de una tercera persona, traen una serie de problemas, difíciles de solucionar. Si se preguntara a las parejas sobre las tensiones íntimas que pueden brotar de estos procedimientos, querrían los esposos someterse a encuestas e interrogatorios que violan el respeto que merecen su pudor e intimidad conyugal?

¿Cómo se siente el varón que sabe que es estéril? ¿Qué clase de reproches pueden brotar en el seno de la relación conyugal? ¿Qué elementos tiene la ley para 
determinar si un hijo es de quien lo gestó, o de quien pagó o pidió el favor de que fuera gestado por una tercera persona?

¿Qué malestares genera la intromisión poco respetuosa de familiares y amigos? Se necesita una dosis muy alta de madurez, de comprensión mutua. A las problemáticas psicológicas se añaden las que surgen de los costos y dificultad de éxito de algunos de estos procedimientos.

¿Se le debe decir al hijo la verdad? ¿Cómo llegar a un acuerdo mutuo en el cual el consenso de la pareja no sea violentado, uno de los dos no asienta por miedo o por sólo satisfacer al otro?

\section{Actitud de la Iglesia católica ante la infertilidad}

En el terreno de las orientaciones la actitud de la fe cristiana es diáfana: "Los cristianos, lejos de pensar que las conquistas logradas por el hombre se oponen al poder de Dios y que la criatura racional pretende rivalizar con el Creador, están persuadidos de que las victorias del hombre son signo de la grandeza de Dios y consecuencia de su inefable designio" (Vaticano II, G. Spes. 34). La misma constitución afirma claramente la justa autonomía de lo creado (No. 36.41).

Ante la "pregunta que se hace la Bioética: ¿qué criterios morales se deben aplicar para clarificar los problemas de la Biomedicina?" se afirma: "El presupuesto para una adecuada respuesta es una antropología integral. La ley moral natural no es una normatividad simplemente biológica, sino que ha de ser concebida como el orden racional por el cual el hombre es llamado a dirigir su vidà ý sus à̉ctos".

"Cualquier intervención biomédica no alcanza únicamente a los tejidos, órganos y funciones sino que afecta a la persona como un todo; por eso estas intervenciones tienen un significado y una responsabilidad morales..." (J.H. Peláez, Seminario de Bioética, Universidad Javeriana, 1995, 47, 57).

"Se afirma con toda nitidez la dignidad sagrada de la persona, lo cual impide que sea tratada como un objeto. La persona es don y vocación, realidad interpersonal, ser social, dotada de racionalidad, etc.

"Se afirma la unidad integral del ser humano; de esta afirmación se siguen consecuencias muy importantes:

- El cuerpo humano no puede ser reducido a tejidos, órganos y funciones.

- Cualquier intervención sobre el cuerpo afecta a toda la persona.

- Sobre la vida física se apoyan y desarrollan los demás valores de la persona.

- Concebir una nueva vida exige una reproducción humana digna "(Ibid)".

Desde aquí podemos trazar unas líneas muy generales, que deben ser trabajadas más cuidadosamente: la bioética no puede quedar prisionera de una concepción estática del hombre y de la naturaleza. La persona no es un émulo de Dios cuando hace ciencia; ésta es revelación de la verdadera identidad del hombre: Dios to ha hecho señor responsable y lo invita a crear un mundo más humano, en el cual los hombres seamos respetados como hijos de Dios.

La ciencia, al abrir horizontes maravillosos y posibilidades antes insospechadas no debe absolutizar ni sus métodos, ni sus conquistas, ni convertirlos en fines absolutos, su sentido y razón de ser está en servir el verdadero crecimiento de la persona y de la comunidad humana. 